\title{
Successful management of extremely frequent hives in children with multiple food allergies with integrative traditional Chinese medicine therapy
}

\section{Fan Xiawen}

Mount Sinai School of Medicine: Icahn School of Medicine at Mount Sinai

Misu Paul

NYU Winthrop Hospital

Tory McKnight ( $\nabla$ tmcknigh@student.nymc.edu )

New York Medical College School of Medicine https://orcid.org/0000-0002-0239-3034

Song Park

Icahn School of Medicine at Mount Sinai

Danna Chung

Icahn School of Medicine at Mount Sinai

Xiu-Min Li

New York Medical College

\section{Case report}

Keywords: food allergens, FPDTH, diarrhea, anxiety, eczema, environmental allergies

Posted Date: December 4th, 2020

DOl: https://doi.org/10.21203/rs.3.rs-120499/v1

License: (9) (i) This work is licensed under a Creative Commons Attribution 4.0 International License.

Read Full License 


\section{Abstract}

\section{Background}

Food allergy is becoming increasingly common among the pediatric population. Despite strict avoidance of food allergens, a subgroup of sensitive individuals still develop frequent, persistent and difficult to treat hives (FPDTH) for which there is no curative therapy. Although these cases are rare, these patients are in most need of therapy.

\section{Case Description}

This is a retrospective review of 3 pediatric patients with highly sensitive food allergy who initially presented with hives daily or every other day, but achieved marked remission after traditional Chinese medicine (TCM) therapies. Patient 1 (P1) is a 5-year-old who had experienced 140 reactions in his lifetime. Reactions were mostly hives with 4 episodes of anaphylaxis. P1 had used Prednisone 20 times, had an Epinephrine injection 4 times and had 3 emergency room (ER) visits. Patient 2 (P2) is a 12-yearold who had experienced hives since age 3 . Despite daily antihistamine use, $\mathrm{P} 2$ had $>730$ reactions in his lifetime at the time of presentation including 2 episodes of anaphylaxis. He had been prescribed prednisone 4 times, an Epinephrine injection 2 times and had 1 ER visit. Patient 3 (P3) is a 20-month-old girl who had experienced $>120$ reactions including 1 episode of anaphylaxis. She was on daily desonide and frequently used and antihistamine, yet still had required a course of prednisone once, an Epinephrine injection once and had $1 \mathrm{ER}$ visit to manage her reaction. After presenting to our clinic, patients received internal and external TCM treatments, including herbal bath and creams (Remedy A-D) as basic remedies to reduce food reactions, including but not limited to frequent hives. Within 7-9 months of TCM treatment, remarkably all patients had complete remission of atopic symotoms. All three patients also experienced improvement in other conditions including food intolerance, diarrhea, anxiety, eczema, environmental allergies. After 1 year of treatment, all three patients had reductions in food-specific lgE levels that had been previously elevated, and additionally, P1 and P3, who initially had high total IgE levels, experienced marked decrease in total IgE levels as well. All three patients continued to introduce foods into their diet that they previously had reactions to, and all 3 patients remain symptom-free.

\section{Conclusions}

Three pediatric patients with known history of multiple food sensitivities and physician diagnosed food allergies that presented with FPDTH underwent TCM regimen and experienced dramatic improvement in symptoms and reduction in their IgE levels. This regimen appears to be effective in FPDTH population although further study in a controlled clinical setting is required.

\section{Background:}

Food allergy affects nearly $5 \%$ of adults and $8 \%$ of children and the health and economic effect of food allergy is vast and growing because of health care expenses and social, industrial and regulatory effects 
$(1,2)$. Food allergic reactions involve multiple systems including, skin (rash and hives), respiratory (cough and wheezing), and gastrointestinal (diarrhea). In the most severe cases anaphylaxis occurs. The skin is the most frequently affected target organ in food intolerance, the most common manifestation is acute urticaria, and there is food aggravated chronic urticaria (3). Hypersensitive skin disorders, such as Contact Urticaria, were shown to have strong associations with multiple food allergies (4). Although foodinduced allergic reactions including skin symptoms is often triggered by ingestion, it can also be triggered by skin contact or inhalation of vapors from cooking food in very sensitive individuals (5). Currently there are no FDA approved food allergy treatment options. Strict avoidance of food allergens, early recognition, and management of reactions are the important measures to prevent serious consequences (6). Unfortunately, despite strict avoidance, some children with multiple food allergies are hypersensitive to minute triggers in the environment or skin contact to offending foods. They experience frequent, persistent and difficult to treat hives (FPDTH) for which there is no curative therapy. Hypersensitive individuals are also susceptible to environmental stimuli, such as temperature changes, making it difficult to control non-allergic and allergic reactions.

Generally, for urticaria management, second generation antihistamines are the first recommendation, however overtime dose can increase fourfold. If symptoms persist, omalizumab, cyclosporine, or short courses of corticosteroids can be considered (7-9). Omalizumab has been used in management of difficult-to-control asthma, chronic urticaria, refractory atopic dermatitis and food allergy with some positive results, but it is not disease modifying, as patient's symptoms recur after stopping treatment, and in certain populations the benefit in clinical outcome versus cost ratio is low (9-13).

There is limited data available for the rare group of children with history of multiple food allergies and hypersensitive reactions to minute exposure with chronic persistent symptoms that adversely affect their quality of life. TCM has been studied as an alternative in treating many chronic allergic disorders. Previous studies have shown that Traditional Chinese medicine (TCM) is safe and effective in treating asthma in several randomized, controlled trials (14-18). TCM has also been studied for treating food allergy, Food Allergy Herbal Formula-2(FAHF-2) has been studied in murine model and patient population (19-21). And there are case reports about successful prevention of frequent severe food anaphylaxis in children with TCM therapy (22). TCM seem to effectively improve the symptoms and decrease the disease severity in patients with moderate to severe atopic dermatitis (23), a study also showed that combination of TCM and antihistamine had better clinical outcome compared to using antihistamine alone in treating chronic urticaria (24). The underlying mechanism of TCM effect could be from the regulatory effect on helper T cells, B cells, macrophages or mast cells, resulting cytokine level changes contributing to anti-inflammatory activity (25).

This is a retrospective case study of three pediatric patients with chronic persistent non-resolving cutaneous manifestations of hives who had dramatic symptom improvement following TCM therapy.

\section{Methods:}


Retrospective review of 3 pediatric patients with highly sensitive food allergy that experienced frequent hives daily or every other day. Patients received internal and external TCM treatments, including herbal bath and creams (Remedy A-D) as basic remedies, to reduce food reactions, including frequent hives. For

all 3 patients, laboratory testing data on liver and kidney function were within the normal range during the entire course of the treatment. Patients were seen at the Ming Qi Natural Health Care Center, and Comprehensive Allergy and Immunology, Integrative Health and Acupuncture in New York.

\section{Case 1:}

Patient $1(\mathrm{P} 1)$ is a 5-year-old male diagnosed with egg allergy at 11 months old after having a major reaction with widespread full body hives, nasal congestion, sneezing, runny nose, watery eyes, and severe itching. P1 continued to develop more food allergies including peanut and milk at 12 months old, and started having more frequent reactions. In the two years prior to TCM therapy, P1 had 140 reactions, mostly hives but including 4 episodes of anaphylaxis. He had used Prednisone 20 times, an Epinephrine injection 4 times and had 3 Emergency Room (ER) visits related to his food sensitization. His use of antihistamines 140 times was consistent with his number of allergic reactions [Table 1]. Three months prior to TCM, his skin reactions became more frequent with daily hives. P1 also has asthma with virus induced wheezing, allergic rhinitis, and eczema. He has a history of fire ant anaphylaxis.

P1 received TCM basic remedies with addition of Digestion Tea (Supplemental method 1). During the first three months of TCM, the number of episodes declined from daily to none (Table I). During 4-6 months of TCM, he had only one episode of hives, and his asthma, appetite, eczema and fire ant allergy improved. At 12 months of TCM, his total and peanut- specific IgE reduced by half. The goal of reducing allergic reactions was achieved within 7-9 months of TCM therapy. By 1.5 year of TCM he continued to have no hives and began to introduce foods, like egg and wheat, beans which he previously had reactions to.

\section{Case 2}

Patient 2 (P2), a 12-year-old male with physician diagnosed food allergies (FA) at 10 years old after having first reaction to pistachio nut, with hives, swollen lips/eyes and a nosebleed. His food-specific lgE levels were not markedly increased and total IgE levels were normal, however he reacted to egg, milk, wheat, peanut, soy, cod, mango, and tomato. At 11 years old he developed severe reactions following a hazelnut skin test. He experienced hives since age 3 and took antihistamines daily. He took cetirizine 5 $\mathrm{mg}$ and loratadine $10 \mathrm{mg}$ twice daily from age 3 to 6 , then diphenhydramine, twice daily from age 6 to 12 , as per his allergist. One month prior to TCM Therapy, he started fexofenadine $180 \mathrm{mg}$, twice daily as per his allergist to manage hives, but he continued to get hives and it become more difficult to control. He had nearly daily hives, and sometimes more than one episode of hives per day. Although most reactions expressed as hives, he also had severe reactions that required epinephrine, prednisone, and ER visits (Table 1). He was also diagnosed with generalized anxiety disorder and Tourette's syndrome at ages 7 and 10 , respectively, and has had tics since age 5 . He experienced diarrhea episodes nearly once a month and his skin is highly sensitive to touch. He also experienced reflux. Given his frequent hives, his primary 
physician also suggested his tryptase and prostaglandin D2 levels measured to assess for possible mast cell activation syndrome, however both were within normal range.

P2 began TCM therapy October 2014 with the goal of reducing his allergic reactions and improve his general health His TCM regimen included Remedy B and D with addition of Good Mood tea (Supplemental method 1) and Pruni Mume and Phellodendri formula (Mei Huang Tea as previous described with the addition of Remedy G Digestion Tea tea) at six months. During 7-9 months of TCM treatment, P2's hives episodes reduced to 0 (Table 1) and his food specific IgE levels also started to decrease (Fig 1). His diarrhea episodes, tics, and anxiety also improved. The goal of reducing allergic reactions, specifically hives, was achieved within 12 months of TCM therapy. After two years of TCM, he was tapered off of fexofenadine without recurrence of hives and started food challenges. By three years of TCM, he passed all challenges to offending foods he previously had reactions to. His allergist believes he no longer has food allergies, and P2 is now tapering off TCM therapy.

\section{Case 3}

Patient 3 (P3) is a 20-month-old female with physician diagnosed multiple food sensitivity and allergies, and frequent, persistent, difficult to treat hives and moderate-to-severe eczema. P3 was diagnosed with severe eczema by dermatologists at 3 months old and evaluated by an allergist for multiple food allergies at 8 months old. She had extreme pruritus, even on daily desonide. Her parents refused oral steroids because of concern over adverse effects at her young age. At 3-7 months old she began reacting to milkbased formula, soy-based formula, and elemental formula. IgE analysis revealed sensitization to dairy, wheat, soy, egg, peanut and rye. Although most reactions were hives, at 14 months, she experienced anaphylaxis from a veggie burger, and was treated with epinephrine at ER and discharged with prednisone and Ranitidine. Subsequent testing revealed additional sensitivities to sunflower and sesame seeds, tree nuts, and many legumes. After the anaphylactic incidence, her hives increased to daily occurrence of frequent, persistent and difficult to treat hives. She also suffered from severe environmental allergies, diarrhea up to eight times a day, and anxiety towards water.

P3 began TCM therapy in July 2015 to reduce hives and food reactions. Her regimen included Remedy A added to Bath Additive, Remedy F, and Remedy K. Within nine days of TCM Therapy, the eczema on her face and the thick, crusty cradle cap on her scalp were gone. Within three months of TCM, her episode of hives reduced to 1 episode during a three months of period, for which she did not use antihistamines, compared to previous 90 episodes per 3 months. After six months of TCM therapy, she was completely hives free. Her eczema, environmental allergies, chronic diarrhea, appetite and growth all improved as well. After one year of TCM, P3's food specific IgE levels were reduced at 1year follow-up test. She began to introduce foods to her diet including vegetables, fruits and beans, and she is still hives free. She continues on TCM with the goal of introducing more foods to her diet.

\section{Discussion:}


This case study describes three patients with known history of multiple food sensitivities and physician diagnosed food allergies that presented with severe persistent and difficult to treat cutaneous manifestations of hives. These three patients underwent TCM therapy with the goal of reducing the frequency and severity of their daily clinical symptoms of hives. Although these cases are noted to be rare and in severely hypersensitive children, this group of pediatric patients are in the most need of therapy. Even with strict avoidance, these patients continue to suffer from almost daily hives and multiple food allergy sensitivities. In the study, the three patients had significant clinical improvement including decreased frequency and eventually elimination of skin reaction episodes, increased tolerance to food allergens, improvement of other allergy related conditions (eczema, asthma, environmental allergies) and improvement of general health (appetite, growth, mood). They also became less dependent and eventually went off antihistamines and steroids. Additionally, there were notable decreases in total lgE and allergen specific IgE levels to both environmental and food antigens (Fig. 1). Although the food specific IgE concentration does not necessarily correlate with clinical tolerance to the food, the increased tolerance is accompanied by decreased IgE levels in OIT studies (26).

However, there are limitations to this report given the retrospective design, including recall bias, possible over-interpretation, and the fact that it was not a controlled study.

Currently, there is little information available for treatment of pediatric patients with frequent, persistent and difficult to treat hives. There are no previously reported studies of persistent and difficult to treat hives prior to this study. This study highlights TCM therapy as a potential to provide effective therapeutic treatment in children with multiple food sensitivities and FPDTH. In this study, all 3 cases demonstrated remarkable improvement with the combined TCM therapy for patients. Future prospective clinical studies and investigation of the mechanism underlying the effect are needed.

\section{Declarations}

\section{Acknowledgment:}

Authors want to thank the families and patients for their excellent effort during the course of TCM treatment and for their coordination to help this manuscript.

\section{Ethics approval and consent to participate}

Ethics approval is not applicable in this case.

\section{Consent for publication}

The patient has provided consent for the publication of data in this report.

\section{Availability of data and materials}


The data referenced in this study has not been published elsewhere.

\section{Competing interests}

Xiaowen Fan, MD, Misu Paul,MD, Tory McKnight, Song Park, MS, Danna Chung, MD, and Xiu-Min Li, MD declare no Conflicts of interest related to the current study. Xiu-Min Li received research support from the National Institutes of Health $(\mathrm{NIH}) /$ National Center for Complementary and Alternative Medicine (NCCAM); Food Allergy Research and Education (FARE) and Winston Wolkoff Integrative Medicine Fund for Allergies and Wellness; received consultancy fees from FARE and Johnson \& Johnson Pharmaceutical Research \& Development, L.L.C. Bayer HealthCare LLC; Received grant from Henan University of Chinese Medicine; received royalties from UpToDate; received travel expenses from the NCCAM and

FARE; received practice compensation from the Integrative Health and Acupuncture PC, and is a 157 member of Herbs Springs, LLC, Health Freedom LLC, and General Nutraceutical Technology.

\section{Funding}

No financial support was provided from a third party.

\section{Authors Contributions}

FX, SP and TM contributed by drafting and revising team manuscript. PE and DC contributed to the acquisition of data, interpretation of data and offered revisions to the manuscript. XML contributed to the conception and design, acquisition of data, analysis, interpretation of data, and Revision of manuscript

\section{References}

1 Jones SM, Burks AW, Dupont C. State of the art on food allergen immunotherapy: oral, sublingual, and epicutaneous. J Allergy Clin Immunol. 2014; 133: 318-23.

2 Sicherer SH, Sampson HA. Food allergy: Epidemiology, pathogenesis, diagnosis, and treatment. J Allergy Clin Immunol. 2014; 133: 291-307; quiz 08.

3 Simons FE, Sampson HA. Anaphylaxis: Unique aspects of clinical diagnosis and management in infants (birth to age 2 years). J Allergy Clin Immunol. 2015; 135: 1125-31.

4 Patel BY, Volcheck GW. Food Allergy: Common Causes, Diagnosis, and Treatment. Mayo Clin Proc. 2015; 90: 1411-9.

5 Schichter-Konfino V, Almog M, Bamberger E, Berkowitz D, Kessel A. The significance of allergic contact urticaria to milk in children with cow's milk allergy. Pediatr Allergy Immunol. 2015; 26: 218-22.

6 Lin C, Lee IT, Sampath V, et al. Combining anti-lgE with oral immunotherapy. Pediatr Allergy Immunol. 2017; 28: 619-27. 
7 Zuberbier T, Aberer W, Asero R, et al. The EAACI/GA(2) LEN/EDF/WAO Guideline for the definition, classification, diagnosis, and management of urticaria: the 2013 revision and update. Allergy. 2014; 69: 868-87.

8 Amin P, Levin L, Holmes SJ, Picard J, Bernstein JA. Investigation of patient-specific characteristics associated with treatment outcomes for chronic urticaria. J Allergy Clin Immunol Pract. 2015; 3: 400-7.

9 Maurer M, Rosén $\mathrm{K}$, Hsieh HJ, et al. Omalizumab for the treatment of chronic idiopathic or spontaneous urticaria. N Engl J Med. 2013; 368: 924-35.

10 Miller CW, Krishnaswamy N, Johnston C, Krishnaswamy G. Severe asthma and the omalizumab option. Clin Mol Allergy. 2008; 6: 4.

11 Tadrous M, Khuu W, Lebovic G, et al. Real-world health care utilization and effectiveness of omalizumab for the treatment of severe asthma. Ann Allergy Asthma Immunol. 2017.

12 Wang HH, Li YC, Huang YC. Efficacy of omalizumab in patients with atopic dermatitis: A systematic review and meta-analysis. J Allergy Clin Immunol. 2016; 138: 1719-22.e1.

13 Lisann L, Song Y, Wang J, Ehrlich P, Maitland A, Li XM. Successful prevention of extremely frequent and severe food anaphylaxis in three children by combined traditional Chinese medicine therapy. Allergy Asthma Clin Immunol. 2014; 10: 66.

14 Jones SM, Pons L, Roberts JL, et al. Clinical efficacy and immune regulation with peanut oral immunotherapy. J Allergy Clin Immunol. 2009; 124: 292-300, 00.e1-97.

15 Chang TT, Huang CC, Hsu CH. Clinical evaluation of the Chinese herbal medicine formula STA-1 in the treatment of allergic asthma. Phytother Res. 2006; 20: 342-7.

16 Hsu CH, Lu CM, Chang TT. Efficacy and safety of modified Mai-Men-Dong-Tang for treatment of allergic asthma. Pediatr Allergy Immunol. 2005; 16: 76-81.

17 Kelly-Pieper K, Patil SP, Busse P, et al. Safety and tolerability of an antiasthma herbal Formula (ASHMI) in adult subjects with asthma: a randomized, double-blinded, placebo-controlled, dose-escalation phase I study. J Altern Complement Med. 2009; 15: 735-43.

18 Wen $\mathrm{MC}$, Wei $\mathrm{CH}, \mathrm{Hu} \mathrm{ZQ}$, et al. Efficacy and tolerability of anti-asthma herbal medicine intervention in adult patients with moderate-severe allergic asthma. J Allergy Clin Immunol. 2005; 116: 517-24.

19 Chan CK, Kuo ML, Shen JJ, See LC, Chang HH, Huang JL. Ding Chuan Tang, a Chinese herb decoction, could improve airway hyper-responsiveness in stabilized asthmatic children: a randomized, double-blind clinical trial. Pediatr Allergy Immunol. 2006; 17: 316-22. 
20 Srivastava KD, Bardina L, Sampson HA, Li XM. Efficacy and immunological actions of FAHF-2 in a murine model of multiple food allergies. Ann Allergy Asthma Immunol. 2012; 108: 351-58.e1.

21 Wang J, Jones SM, Pongracic JA, et al. Safety, clinical, and immunologic efficacy of a Chinese herbal medicine (Food Allergy Herbal Formula-2) for food allergy. J Allergy Clin Immunol. 2015.

22 Wang J, Li XM. Chinese herbal therapy for the treatment of food allergy. Curr Allergy Asthma Rep. 2012; 12: 332-8.

23 Liu J, Mo X, Wu D, et al. Efficacy of a Chinese herbal medicine for the treatment of atopic dermatitis: a randomised controlled study. Complement Ther Med. 2015; 23: 644-51.

$24 \mathrm{Li} \mathrm{XM}$, Brown L. Efficacy and mechanisms of action of traditional Chinese medicines for treating asthma and allergy. J Allergy Clin Immunol. 2009; 123: 297-306; quiz 07-8.

25 Wuthrich B. Food-induced cutaneous adverse reactions. Allergy. 1998; 53:131-5.

26 Yuan S, Guan J, Hao Y, Chai J, Gao F, Shi S, et al. Effectiveness and Safety of the Combination of the Traditional Chinese Medicine Prescription Jade Screen and Desloratadine in the Treatment of Chronic Urticaria: A Systematic Review and Meta-Analysis of Randomized Controlled Trials. Evidence-Based Complement Altern Med. 2017; 2017:1-11.

\section{Tables}

Table 1. Frequency of reaction, medication use and ER visits before, during and after TCM therapy 


\begin{tabular}{|c|c|c|c|c|c|c|c|}
\hline \multirow{2}{*}{$\begin{array}{l}\text { \# of Uses or } \\
\text { Occurrences }\end{array}$} & \multicolumn{2}{|c|}{ Before TCM } & \multirow[b]{2}{*}{$\begin{array}{c}\text { Prior } 1 \\
\text { M }\end{array}$} & \multicolumn{4}{|c|}{ During and after the courses of TCM } \\
\hline & Total & $\begin{array}{c}\text { Prior } 3 \\
\text { M }\end{array}$ & & $1-3 \mathrm{M}$ & $4-6 \mathrm{M}$ & $7-9 \mathrm{M}$ & $10-12 \mathrm{M}$ \\
\hline \multicolumn{8}{|l|}{ Patient 1 (EL) P } \\
\hline Allergic Reactions & 140 & 90 & 30 & 0 & 1 & 0 & 0 \\
\hline Epinephrine & 4 & 0 & 0 & 0 & 0 & 0 & 0 \\
\hline Diphenhydramine & 140 & 90 & 30 & 0 & 0 & 0 & 0 \\
\hline Prednisone & 20 & 1 & 0 & 0 & 0 & 0 & 0 \\
\hline ER visits & 3 & 0 & 0 & 0 & 0 & 0 & 0 \\
\hline \multicolumn{8}{|l|}{ Patient 2 ( 5 yod) } \\
\hline Allergic Reactions & $>730$ & $>90$ & 30 & 90 & 90 & 0 & 0 \\
\hline Epinephrine & 2 & 1 & 1 & 0 & 0 & 0 & 0 \\
\hline Diphenhydramine & $>100$ & $>90$ & 30 & 1 & 1 & 0 & 0 \\
\hline Prednisone & 4 & 1 & 0 & 0 & 0 & 0 & 0 \\
\hline ER visits & 1 & 1 & 0 & 0 & 0 & 0 & 0 \\
\hline \multicolumn{8}{|c|}{ Patient 3 (20 month old) } \\
\hline Allergic Reactions & $>120$ & $>90$ & 30 & 1 & 0 & 0 & 0 \\
\hline Epinephrine & 1 & 0 & 0 & 0 & 0 & 0 & 0 \\
\hline Diphenhydramine & $>45$ & 45 & 15 & 0 & 0 & 0 & 0 \\
\hline Prednisone & 1 & 0 & 0 & 0 & 0 & 0 & 0 \\
\hline ER visits & 1 & 0 & 0 & 0 & 0 & 0 & 0 \\
\hline
\end{tabular}

\section{Figures}




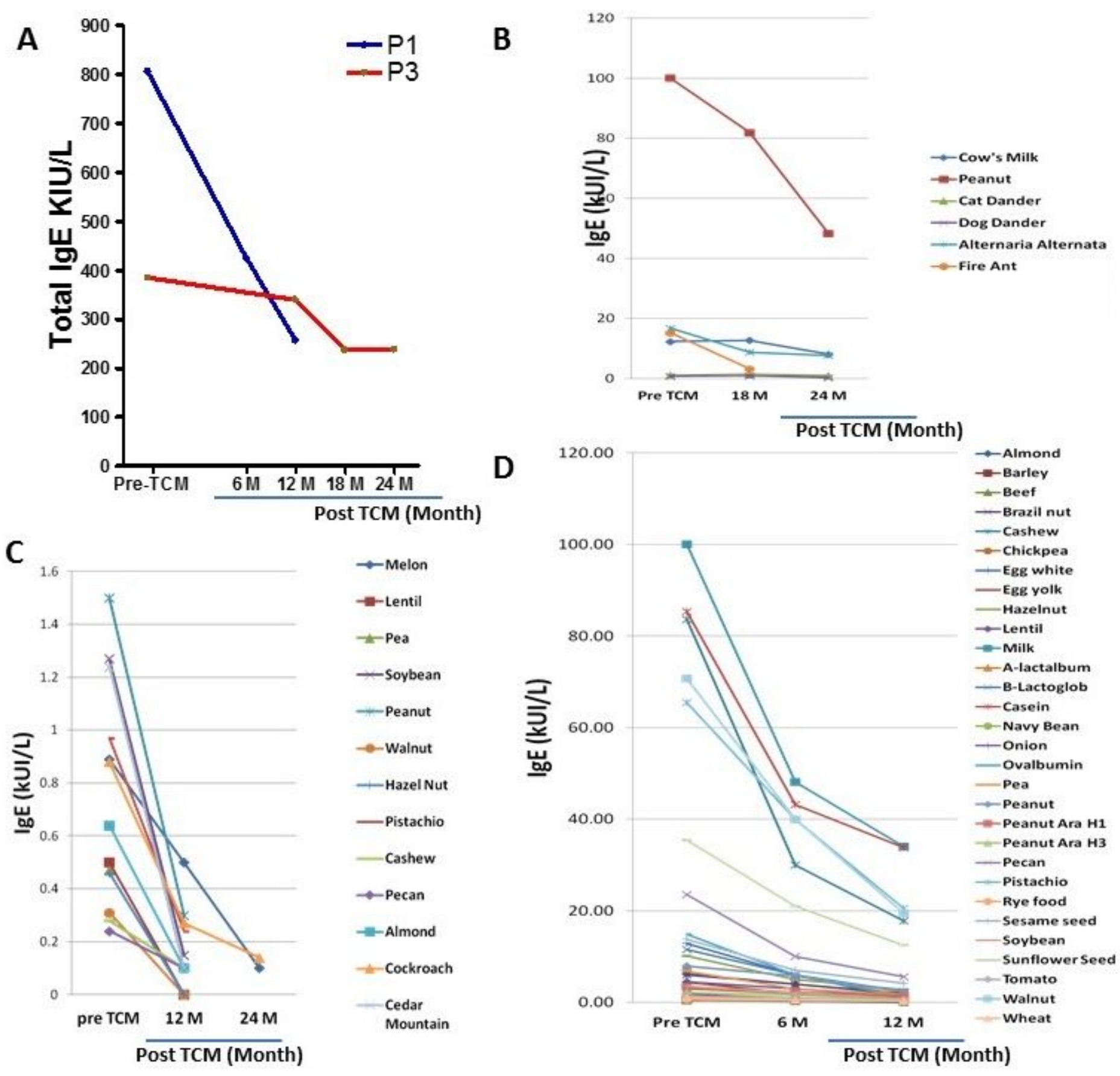

Figure 1

Total and antigen specific IgE levels. (A) Total IgE levels changes in the patients 1 (Blue line) and 3 (red line). P2 had low total IgE levels that were not included in the figure. Total IgE levels bloods were measured just pre-treatment (Pre-TCM), 6, 12,18, and 24 month (M) after treatment started. (B) Antigen specific lgE levels of P1. (C) Antigen specific lgE levels of P2. (D) Antigen specific lgE levels of P3 before and after TCM therapy. 


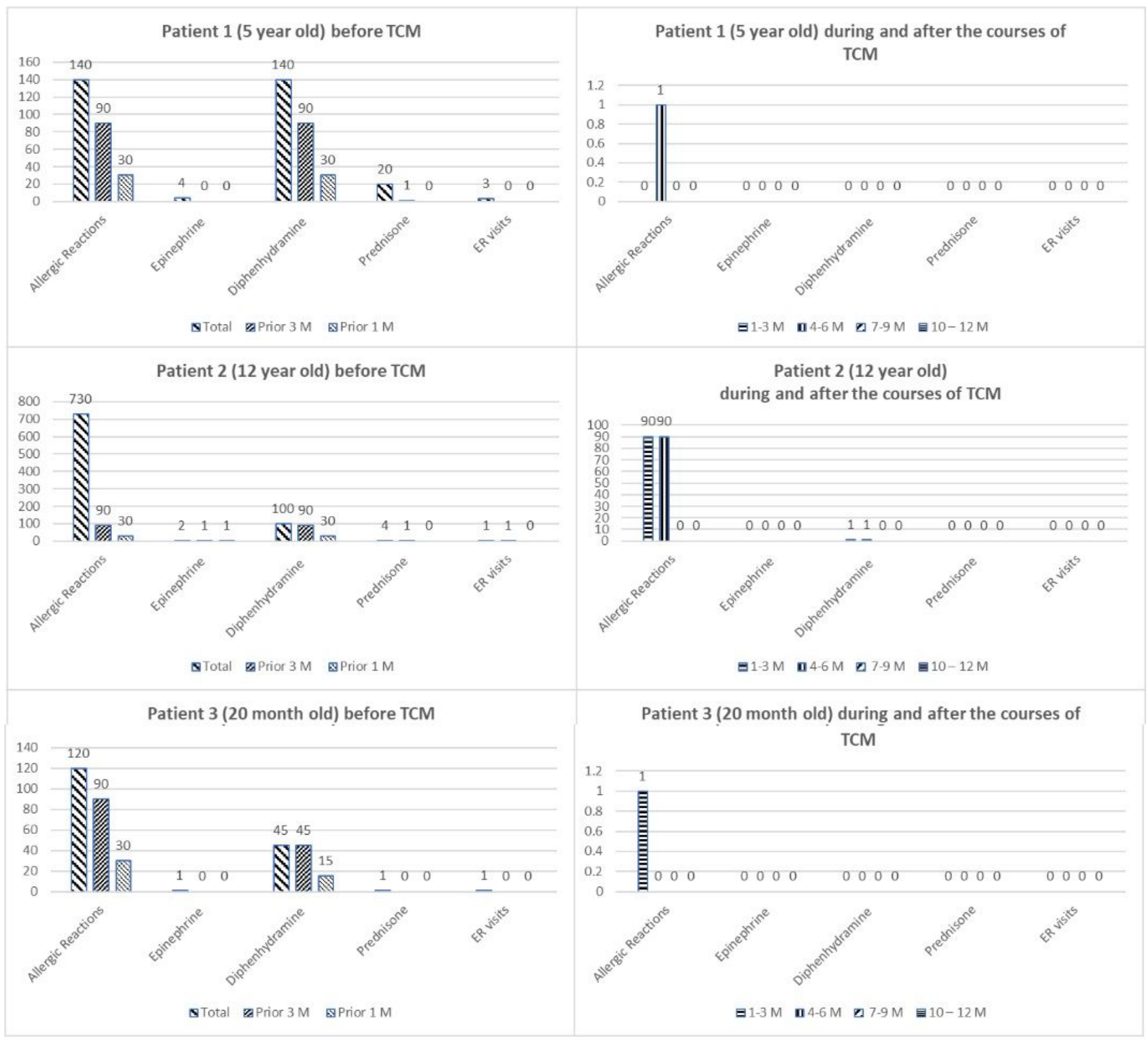

Figure 2

Frequency of reaction, medication use and ER visits before, during and after TCM therapy 